S. Shatokhina, Researcher,

V. Golovnia, Researcher,

V. Andruk, Researcher,

MAO NAS of Ukraine, Kyiv

\title{
ASTEROIDS SEARCHING, REDISCOVERY AND ORBIT CORRECTION WITH UKRVO RESOURCES
}

Modern approach to processing early photographic observations from Joint Digital Archive of Ukrainian Virtual Observatory (UkrVO) with new technologies can be an effective instrument for rediscovery of asteroids and correction their orbits. Using of techniques digitization of astronegatives and further processing of observations of Northern Sky Survey (FON) and of other projects are applied for broad search for images of minor planets. From analysis of 93 plates of the 8 zone FON we obtained 150 positions and B-magnitudes of asteroids. Analysis of the differences (O-C) was made.

Keywords: UkrVO, minor planets.

С. Шатохина, науч. сотр.,

В. Головня, науч. сотр.,

В. Андрук, науч. сотр.,

Главная астрономическая обсерватория НАН Украины, Киев

\section{РЕСУРС УКРВО ДЛЯ ЗАДАЧ ПОИСКА, ПЕРЕОТКРЫТИЯ И УТОЧНЕНИЯ ОРБИТ АСТЕРОИДОВ}

Ядром Украинськой виртуальной обсерватории (УкрВО) является объединенный цифровой архив наблюдений, проведенных в течении двадцатого века в обсерваториях Украини. По данным результатов сканирований и обработки нескольких тысяч пластин наблюдательных программ ФОН, ОРБИТА получено более 150 положений и звездных величин астероидов. Разработаная и внедренная в ГАО НАН Украини технология обработки цифровых изображений позволяет добиться высокой точность результатов. Предварительный анализ полученных данных указывает на целесообразность использования фотографических наблюдений прошлых 1950-1990 годов.

Ключевые слова: УкрВО, малые планеты.

УДК 523.45/.48, 52-14

О. Їжакевич, молодш. наук. співроб.,

В. Андрук, наук. співроб.,

Л. Пакуляк, канд. фіз.-мат. наук, Головна астрономічна обсерваторія НАН України, Київ; В. Лук'янчук, магістр,

Київський національний університет імені Тараса Шевченка, Київ

\section{ФОТОГРАФІЧНІ СПОСТЕРЕЖЕННЯ ВЕЛИКИХ ПЛАНЕТ ТА ÏХ СУПУТНИКІВ У ГАО НАН УКРАÏНИ В 1961-1990 pp.}

\begin{abstract}
У межах національного проекту "Українська віртуальна обсерваторія" проведено роботи зі створення каталогів астрономічних положень і зоряних величин великих планет та їх супутників на базі фотографічних спостережень, виконаних у ГАО НАН Укріїни за допомогою чотирьох телескопів упродовж 1961-1990 р. Завдяки програмному комплексу, розробленому в ГАО для редукції оцифрованих астронегативів, виконано редукцію спостережень супутників Сатурна (S2-S9), а також Урана, Нептуна та їх супутників U1-U4, N1. За опорну систему слугувала система зоряного каталогу ТYСНО2. Внутрішня точність визначення положень становить $\pm 0.09- \pm 0.25$ агсsес. На даний час виконується аналогічна редукція рядів фотографічних спостережень Нептуна, Урана та їх супутників, що були отримані в ГАО за цей самий період.
\end{abstract}

Ключові слова: каталоги, тіла Сонячної Системи, Сатурн, Уран, Нептун.

Вступ. База даних фотографічних спостережень DBGPA, налічує значну кількість платівок з тілами Сонячної Системи. Частково ці спостережень опрацьовувалися раніше в міру їх накопичення з прив'язкою до різних каталожних систем [1-5]. Ми поставили собі за мету - переопрацювати ці спостереження на сучасному рівні із залученням єдиної опорної системи каталогу ТYСНО-2 [6-8, 14]. Завдяки комплексу програм, розробленому у відділі астрометрії та відлагоджених в операційній системі LINUX-MIDAS-ROMAFOT, була виконана редукція цих спостережень.

Основні ряди спостережень були отримані безпосередньо в ГАО у 1961-1984 р. за допомогою двох астрографів: DLFA (D/F=40/550) та DWA (D/F = 40/200). Окрім того, в експедиційних умовах (в Узбекистані), отримано декілька коротких рядів фротографрічних спостережень за допомогою астрографа Цейса $D A Z$ (D/F=40/300) і рефрлектора Z600. Табл. 1 дає більш детальну інформацію про параметри телескопів та фротоматеріали.

Таблиия 1

Деякі характеристики спостережного матеріалу

\begin{tabular}{|c|c|c|c|c|c|c|}
\hline Telescope & $\mathbf{F}, \mathbf{m m}$ & Scale, "/mm & Field, deg & Size, $\mathbf{m m}$ & Bandwidth & Type, emulsion \\
\hline DLFA I & 5500 & 38.47 & $2.5 \times 2.5$ & $240 \times 240$ & Bph & Agfa Astro, ORWO-ZU21, -ZU2 \\
\hline DLFA II & 5500 & 38.47 & $1.8 \times 2.5$ & $160 \times 240$ & Vph & ORWO-NP27 \\
\hline DWA I, II & 2000 & 103.13 & $8.0 \times 8.0$ & $300 \times 300$ & Bph & ORWO-ZU21 \\
\hline DAZ I,II & 3000 & 68.80 & $5.5 \times 5.5$ & $300 \times 300$ & Bph & Bph \\
\hline Z-600 & 7500 & 27.5 & $0.5 \times 0.5$ & $90 \times 120$ & $\begin{array}{c}\text { ORWO-ZU21, -ZU2 } \\
\text { ORWO-NP27 }\end{array}$ \\
\hline
\end{tabular}

Супутники Сатурна. 3 архіву Бази даних фотографічних спостережень DBGPA було вибрано понад 250 фотопластинок із можливими зображеннями головних супутників Сатурна (S2-S9). Раціональна конструкція Бази даних сприяла зручному пошуку та вибору потрібної інформації. Усі спостереження виконано силами співробітників ГАО. На рис. 1 показано активність і результативність окремих спостерігачів за цей період. Методика фотографічних спо- 
стережень супутників Сатурна полягала в тому, що на одну й ту саму платівку експонували декілька знімків різної тривалості від декількох секунд до декількох хвилин. При цьому платівку зміщували у певному напрямку, зазвичай повздовж меридіана. Такий підхід збільшував шанс виявити слабкі та близькі до Планети супутники. Основними визначальними факторами при пошуку і виявленню супутників на астронегативах $€$ масштаб телескопа, відстань супутника від Планети на даний момент, а також світлосила інструмента. Найпродуктивнішими виявилися спостереження супутників Сатурна на астрографрі DLFA, масштаб якого та роздільна здатність сприяли впевненому визначенню положень супутників S2, S3, S4, S5, S6,S8. На ширококутному астрографі DWA, нажаль, успішними виявилися спостереження тільки двох супутників S6 та S8. Короткотривалий ряд 1986 р. на астрографі DAZ (Кітаб) виявився не дуже успішним через несприятливе розташування супутників. Спостереження у 1990 р. на рефлекторі Z600 підтвердили доцільність застосування рефлекторів для розв'язку астрометричних задач. На рис. 2 показано розподіл спостережень супутників Сатурна уподовж 30 років на різних телескопах.

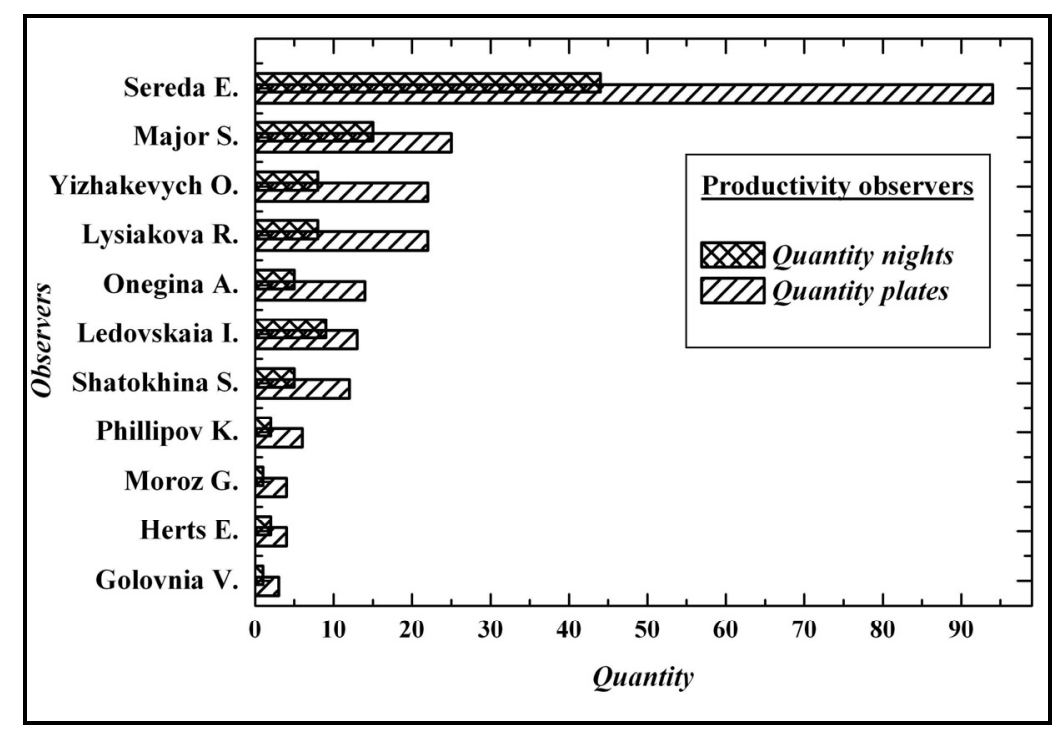

Рис. 1. Активність спостерігачів

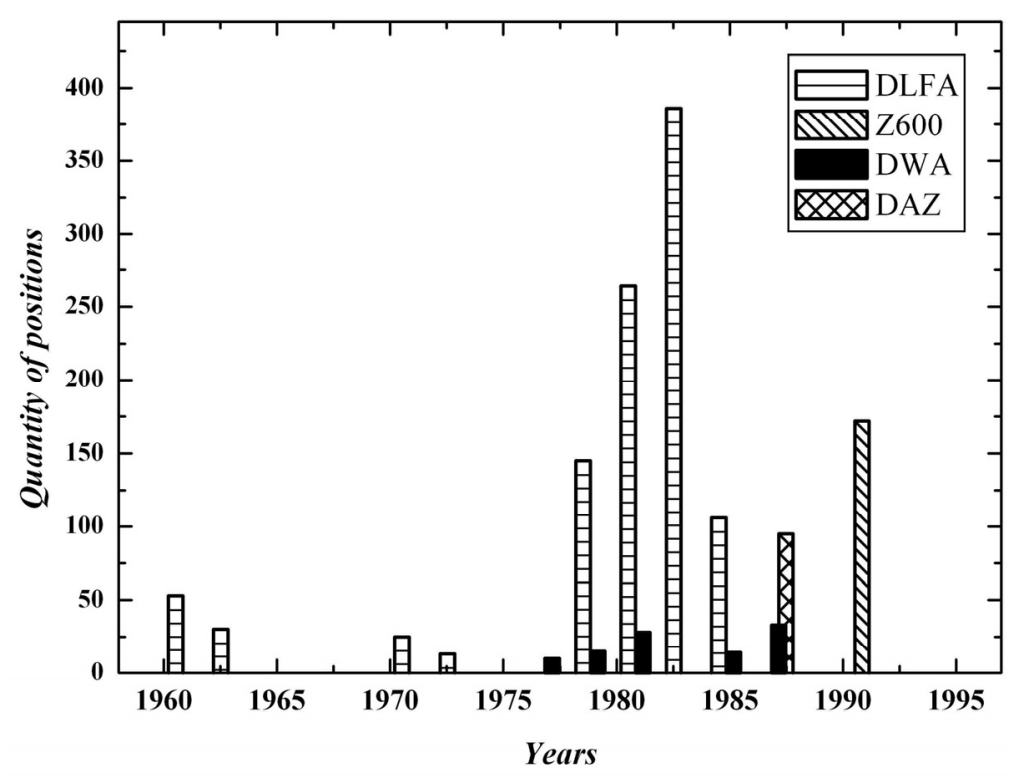

Рис. 2. Розподіл спостережень супутників Сатурна впродовж 30 років

Сучасний рівень космічних досліджень вимагає і сучасних методів виявлення та опрацювання добутої інформації. Новизна методики полягає в тому, що ми маємо справу не ыз самою фотографрічною платівкою, а з її оцифрованим аналогом. Оцифровка платівок здійснювалася на сканері Epson Expression 10000XL (EE) у сірому діапазоні 16 bits з роздільною здатністю $1200 \mathrm{dpi} \mathrm{[9-13].} \mathrm{Зв'язок} \mathrm{між} \mathrm{двома} \mathrm{системами,} \mathrm{системою} \mathrm{прямокутних} \mathrm{координат} \mathrm{X,Y}$ та сферичних $\alpha, \delta$, як відомо, визначається нескінченним степеневим рядом, члени якого залежать від багатьох фракторів. Обчислення за цими формулами можливе лише після прийняття певних обмежень щодо кількості членів степеневого ряду. Варіюючи цією кількістю, ми отримуємо результат з різним рівнем точності. Чим більше каталожних зірок потрапляє на платівку, тим точніше можна здійснити зв'язок між двома координаційними системами.

Спостережний матеріал було отримано за допомогою телескопів з різними характеристиками, з різною кількістю каталожних зірок, що потрапляють на платівки. Тому і кількість членів редукційних формул індивідуальна для кожно- 
го телескопу. При редукції спостережень на астрографі DWA (середня кількість зір на платівці $n=\sim 610$ ) та астрограсрі DAZ (середня кількість зір $n=\sim 142$ ) застосовувався поліном шостого ступеня (27 членів). Редукція спостережень з телескопа DLFA $(n=\sim 75)$ здійснювалася із застосуванням полінома третього ступеня, а спостереження, отримані на рефлекторі Z600 ( $n=\sim 16)$ оброблялися за лінійною моделлю.

Про внутрішню точність редукції фротографрічних спостережень супутників Сатурна свідчать дані таблиці 2, де по кожному телескопу наведено імена супутників, кількість ночей спостережень, кількість отриманих платівок та знімків, а також кількість визначених астрометричних положень. В останніх чотирьох стовпчиках таблиці наведено відомості про середньо квадратичні похибки RMS визначення фотографічної зоряної величини, екваторіальних координат $\alpha$ та $\delta$, а також - середнє значення кількості опорних зірок на пластинці.

Таблиця 2.

Результати редукції спостережень супутників Сатурна по кожному телескопу. Внутрішня точність редукції

\begin{tabular}{|c|c|c|c|c|c|c|c|c|c|}
\hline & \multirow{2}{*}{$\begin{array}{c}\text { Saturn's } \\
\text { satellites }\end{array}$} & \multicolumn{4}{|c|}{ Quantity of } & \multicolumn{3}{c|}{ RMS of } & $\begin{array}{c}\text { N } \\
\text { Ref. } \\
\text { stars }\end{array}$ \\
\cline { 3 - 11 } & nights & plates & Snapshots & Positions & Bph & Alpha & Delta \\
\hline DLFA & S2 S3 S4 S5 S6 S7 S8 & 62 & 138 & 344 & 1017 & \pm 0.27 & \pm 0.09 & \pm 0.09 & 75 \\
\hline DWA & S4 S5 S6 S8 & 14 & 30 & 69 & 101 & \pm 0.27 & \pm 0.23 & \pm 0.22 & 610 \\
\hline DAZ & S4 S5 S6 S8 & 7 & 8 & 32 & 95 & \pm 0.34 & \pm 0.09 & \pm 0.10 & 142 \\
\hline Z600 & S3 S4 S5 S6 S7 S8 S9 & 9 & 33 & 66 & 172 & \pm 0.37 & \pm 0.09 & \pm 0.11 & 16 \\
\hline & $\Sigma$ & 92 & 209 & 511 & 1385 & & & & \\
\hline
\end{tabular}

Завершальним етапом редукції є обчислення сферичних координат усіх об'єктів на знімку та пошук серед них супутників Сатурна. Для цього були підготовлені так звані пошукові файли з уточненими моментами (UTC) часу експонування та відповідними передбачуваними координатами об'єктів спостережень.

За допомогою ефемеридних даних IMCCE (теорія TASS 1.7) (http://lnfm1.sai.msu.ru/neb/nss/nssephmr.htm) i завдяки засобам обчислення ефемерид М.В. Ємєльянова для всіх моментів експозицій були визначені (О-С), їх середні значення та похибки середнього (табл. 3). При цьому виявлялися та вилучалися знімки з безрезультатними спостереженнями.

Таблиця 3

Результати редукції спостережень по кожному супутнику Сатурна. Порівняння з теорією

\begin{tabular}{|l|c|c|c|c|c|}
\hline \multicolumn{1}{|c|}{ Saturn's satellites } & Vmg & N nights & N posit. & (O-C) $\boldsymbol{\alpha}$, arcsec & (O-C) $\boldsymbol{\delta}$, arcsec \\
\hline S2 Enceladus & 11.7 & 6 & 12 & $0.48 \pm 0.20$ & $0.16 \pm 0.14$ \\
\hline S3 Tethys & 10.3 & 20 & 96 & $-0.01 \pm 0.06$ & $0.10 \pm 0.04$ \\
\hline S4 Dione & 10.4 & 40 & 184 & $0.07 \pm 0.03$ & $0.07 \pm 0.03$ \\
\hline S5 Rhea & 9.7 & 57 & 269 & $0.15 \pm 0.03$ & $0.07 \pm 0.03$ \\
\hline S6 Titan & 8.3 & 84 & 435 & $0.09 \pm 0.02$ & $-0.03 \pm 0.02$ \\
\hline S7 Hiperion & 14.2 & 8 & 13 & $-0.04 \pm 0.13$ & $0.10 \pm 0.18$ \\
\hline S8 Japetus & 12 & 78 & 375 & $0.11 \pm 0.02$ & $0.04 \pm 0.02$ \\
\hline S9 Phoebe & 16.4 & 1 & 1 & 0.44 & -0.27 \\
\hline
\end{tabular}

Урана та Нептуна, редукція спостережень. Спостереження Урана, Нептуна та їх супутників були виконані за допомогою трьох телескопів: DLFA, DWA, Z600 майже одночасно зі спостереженнями Сатурна (1963-1990р.) Параметри телескопів дозволили виявити 4 супутника Урана (U1, U2, U3, U4) та один супутник Нептуна (N1). Методика редукції цих спостережень подібна до редукції спостережень супутників Сатурна, про які розповідалося вище. Суттєвою різницею є різниця в довжині експозицій - від декількох хвилин до 15-18 хв. У табл. 4 представлено результати редукції по Урану, його чотирьох супутниках (U1,U2,U3,U4), а в табл. 5 - результати по Нептуну та Тритону(N1). У другому стовпчику ліворуч наведено середнє значення обчисленої фотографічної зоряної величини Врh, а в 4-му та 5-му стовпчиках наведено середні значення О-С при порівнянні з теорією DE431 (IMCCE) і похибки цих середніх.

Таблиця 4

Результати редукції фотографічних спостережень Урана та його супутників. (U1-U4). Внутрішня точність редукції

\begin{tabular}{|c|c|c|c|c|c|c|c|c|c|}
\hline & \multirow{2}{*}{ Bph } & \multirow{2}{*}{$\begin{array}{c}\mathbf{N} \\
\text { posit }\end{array}$} & \multirow{2}{*}{$\begin{array}{c}\mathbf{N} \\
\text { pates }\end{array}$} & \multirow{2}{*}{$\begin{array}{l}(0-C) \alpha \\
\operatorname{arcsec}\end{array}$} & \multirow{2}{*}{$\begin{array}{l}(0-C) \delta \\
\operatorname{arcsec}\end{array}$} & \multicolumn{3}{|c|}{ RMS of } & \multirow{2}{*}{$\begin{array}{l}\text { N Ref } \\
\text { stars }\end{array}$} \\
\hline & & & & & & $\mathrm{Bph}$ & Alpha & Delta & \\
\hline U1 Ariel, Z600 & 12.1 & 3 & 3 & $-0.30 \pm 0.68$ & $0.78 \pm 0.42$ & 0.43 & 0.13 & 0.13 & 16 \\
\hline U2 Umbriel, Z600 & 12.6 & 8 & 6 & $-0.16 \pm 0.30$ & $0.31 \pm 0.14$ & 0.47 & 0.11 & 0.12 & 16 \\
\hline U3 Titania, Z600 & 12.6 & 22 & 15 & $0.04 \pm 0.11$ & $0.12 \pm 0.07$ & 0.28 & 0.08 & 0.12 & 17 \\
\hline U4 Oberon, Z600 & 12.8 & 22 & 15 & $-0.09 \pm 0.12$ & $0.10 \pm 0.10$ & 0.32 & 0.08 & 0.12 & 17 \\
\hline U4 Oberon, DWA & 12.5 & 1 & 1 & 0.01 & -0.61 & 0.27 & 0.10 & 0.11 & 1260 \\
\hline All satellits & & 56 & & & & & & & \\
\hline Uranus, DLFA & 9.1 & 9 & 7 & $0.90 \pm 0.20$ & $-0.23 \pm 0.27$ & 0.25 & 0.06 & 0.07 & 101 \\
\hline Uranus, DWA & 6.4 & 29 & 12 & $0.13 \pm 0.15$ & $-0.22 \pm 0.14$ & 0.16 & 0.16 & 0.18 & 877 \\
\hline Uranus, Z600 & 10.6 & 23 & 14 & $0.15 \pm 0.14$ & $0.06 \pm 0.14$ & 0.41 & 0.08 & 0.10 & 17 \\
\hline Uranus, All telesc. & 8.4 & 61 & 33 & $0.25 \pm 0.10$ & $-0.12 \pm 0.09$ & 0.32 & 0.12 & 0.14 & \\
\hline$\Sigma$ & & 117 & 33 & & & & & & \\
\hline
\end{tabular}


Результати редукції спостережень Нептуна та його супутника (N1). Внутрішня точність редукції

\begin{tabular}{|c|c|c|c|c|c|c|c|c|c|}
\hline & \multirow{2}{*}{ Bph } & \multirow{2}{*}{$\begin{array}{c}\mathrm{N} \\
\text { posit }\end{array}$} & \multirow{2}{*}{$\begin{array}{c}\mathrm{N} \\
\text { nights }\end{array}$} & \multirow{2}{*}{$\begin{array}{l}(0-C) \alpha \\
\operatorname{arcsec}\end{array}$} & \multirow{2}{*}{$\begin{array}{l}\text { O-C)ठ } \\
\operatorname{arcsec}\end{array}$} & \multicolumn{4}{|c|}{ RMS of } \\
\hline & & & & & & Bph & Alpha & Delta & N Ref.stars \\
\hline Neptune, DLFA & 8.3 & 3 & 3 & $0.23 \pm 0.26$ & $0.07 \pm 0.20$ & 0.32 & 0.05 & 0.08 & 93 \\
\hline Neptune, DWA & 8.5 & 33 & 14 & $0.20 \pm 0.12$ & $-0.32 \pm 0.17$ & 0.34 & 0.23 & 0.25 & 724 \\
\hline Neptune, Z600 & 9.1 & 15 & 12 & $-0.06 \pm 0.10$ & $0.01 \pm 0.11$ & 0.23 & 0.10 & 0.09 & 16 \\
\hline Neptune, All telesc. & 8.7 & 51 & 29 & $0.12 \pm 0.08$ & $-0.20 \pm 0.12$ & 0.08 & 0.18 & 0.19 & \\
\hline Triton N1, Z600 & 11.5 & 9 & 8 & $0.28 \pm 0.19$ & $0.31 \pm 0.16$ & 0.65 & 0.10 & 0.08 & 16 \\
\hline$\Sigma$ & & 60 & 29 & & & & & & \\
\hline
\end{tabular}

Висновки. Завершена редукція фотограффічних спостережень восьми супутників Сатурна за 1961-1990 р. Опрацьовано 209 фоотографічних платівок (511 знімків). Отримано каталог з 1385 астрономічних положень. Точність редукції, в середньому, з прив'язкою до каталогу ТYСНО2 лежить у межах $\sim \pm 0.09- \pm 0.23$ arcsec. Продовжується редукція спостережень Урана та Нептуна На даний момент опрацьовано 33 платівок із зображеннями Урана та 29 платівок з Нептуном. Загалом отримано каталог 117 астрономічних положень Урана разом із супутниками та каталог 60 положень Нептуна та Тритона. Внутрішня точність редукції спостережень цих об'єктів - $\pm 0.08- \pm 0.25$. Слід відмітити, що точність редукції по телескопу DWA в 2-2.5 раза нижча за точність результатів по інших телескопах.

Робота з опрацювання спостережень Великих планет та їх супутників продовжується.

Створений у ГАО НАН України архів фотоспостережень в рамках проекту УкрВО зберігає в собі інфрормацію про неповторювані події в навколишньому космічному просторі. Сподіваємося, що наша робота з переопрацювання цієї інформації на сучасному технічному рівні може розширити наші знання про планети та їх супутники, які перебувають під збурюючим впливом як з боку планет-гігантів, так і сусідів-супутників.

Список використаних джерел

1. Yizhakevych O. M. Positional Observations of Saturn's satellites at the MAO AS of USSR in 1980 / O. M. Yizhakevych // Scientific paper deposited in All - russian institute of scientific and technical information. - Kyiv, 1991. - № 4553-B91.

2. Positional Observations of Jupiter VI at the Main Astronomical Observatory of the National Academy of Siences of Ukraine / O. M. Yizhakevych, S. V. Kaltygina, S. P. Major, S. V. Shatokhina // Kinematics and Physics of Celestial Bodies, 1991, Vol. 7, № 2. - P. 98.

3. Positional Photogpaohic observations of Jupiter's external satellites in 1987-1988 / O. M. Yizhakevych, S. V. Kaltygina, I. V. Ledovskaya, S. V. Shatokhina // Kinematics and Physics of Celestial Bodies, 1994. Vol. 10, № 1. - P. 88.

4. Kulyk I. The Natural satellite database of the Main Astronomical Observatory of The National Academy of Siences of Ukraine : an overview / Kulyk I., Ye. Yizhakevych, L. Pakuliak // IMCCE. Internat. Workshop NAROO-GAIA "A new reduction of old observationsn the Gaia era". - Paris Observatory, June 2012. - Paris, France. - P. 153-158 [http://hal.upmc.fr/hal-00758312]. - Submitted on 7 May 2013.

5. First results of MAO NASU SS bodies photographic archiv digitizing / L. Pakuliak, V. Andruk, S. Shatokhina et al. // IMCCE Internat. Workshop NAROOGAIA "A new reduction of old observations the Gaia era". Paris Observatory, June 2012. - Paris, France. - P. 161-165 [http://hal.upmc.fr/hal-00821005]. - Submitted on 7 May 2013.

6. Data Processing of Plates Containing Images of Uranus and Neptune from Ukrvo Digital Archive: Structure, Quality Analysis / Yu. Protsyuk, O. Yizhakevych, O. Kovylianska et al. // Odessa Astron. Publ., 2015. - Vol. 28, N 2. - P. 204-206.

7. Yizhakevych O. M. Catalog of Astronomical Positions of Saturn's Moons, Obtained by Photographic Observations on MAO NASU in 1961-1991: Program and Abstracts / O. M. Yizhakevych, L. K. Pakuliak, V. M. Andruk // 15th Odessa Int. Astron. Gamow Conf. School "Astronomy and Beyond: Astrophysics, Cosmology, Cosmomicrophysics, Astroparticle Physics, Radioastronomy and Astrobiology. - Odessa, Aug.16-23, 2015: ,2015.

8. Creating the catalogs of astronomical positions of Saturn's satellites (S1-S8) and Jupiter's outer satelliters (J6-J8) basing on Goloseevo photographical observations database DBGPA : Program and Abstracts / Ye. M. Yizhakevych, L. K. Рakuliak, S. V. Shatokhina et al. (in rus.: Создание каталогов астрономических положений спутников Сатурна (S1-S8) и внешних спутников Юпитера (J6-J8) на основе Голосеевской базы данных фотографических наблюдений DBGPA / Е. М. Ижакевич, Л. К. Пакуляк, С. В. Шатохина и др.) // 14th Odessa Internat. Astron. Gamow Conf. School "Astronomy and Beyond: Astrophysics, Cosmology and Gravitation, Cosmomicrophysics, Radio-Astronomy and Astrobiology". - Odessa, Ukraine, Aug. 17-24, 2014. - P. 38.

9. On application of a scanner for determination of coordinates and photometric characteristics of stras from the FON program plates / V. M. Andruk, G. A. Ivanov, М. T. Pogorel'tsev, A I. Yatsenko (in rus.: Об использовании сканера для определения координат и фотометрии звёзд на пластинках программы ФОН / В. Н. Андрук, Г. А Иванов, М. Т. Погорельцев, А. И. Яценко) // KFNT, 2005. - Vol. 21, № 5. - P. 396-400.

10. Andruk V. M. Photometry of plates digitized using Microtek ScanMaker 9800xl TMA scanner / V. M. Andruk, G. Z. Butenko, A. I. Yatsenko // KPCB, 2010. - Vol. 26, № 3. - P. 146-150.

11. Astrometry of PSA plates digitalized by two kinds of scanners. Separation of images of the stars from two exposures / V. Andruk, G. Ivanov, A. Yatsenko et al. (in ukr.: Астрометрія платівок ДША, оцифрованих двома типами сканерів. Розділення зображень зір двох експозицій / В. Андрук., Г. Іванов, А. Яценко та ін.) // KNUB Astronomy, 2012. - № 48. - Р. 11-13.

12. Golovnia V. Astrometry of the plates of the DWA digitized with the Microtek scanmaker 9800XL TMA / V. Golovnia, V. Andruk, A. Yatsenko (in ukr.: Гoловня В. Астрометрія платівок ПША, оцифрованих сканером MICROTEK SCANMAKER 9800XL TMA / В. Головня, В. Андрук, А. Яценко) // J. of Phys. Studies, 2010. - Vol. 14, № 2. - P. 1-8.

13. Method for evaluating the astrometric and photometric charakteristics of commercial scanners in their application for the scienrific purpose / Yu. I. Protsyuk, V. N. Andruk, M. M. Muminov et al. // Odessa Astron. Publ., 2014. - Vol. 27, N 1. - P. 61-62.

14. Theory of Motion of Selected Saturn's Satellites: Program and Abstracts / O. M. Yizhakevych, V. Troianskyi, A. Bazyey et al. // 15th Odessa Internat. Astron. Gamow Conf. School "Astronomy and Beyond: Astrophysics, Cosmology, Cosmomicrophysics, Astroparticle Physics, Radioastronomy and Astrobiology". - Odessa, Aug.16-23, 2015. - P. 68-69.

Надійшла до редколегії 15.06.16

Е. Ижакевич, мл. науч. сотр., В. Андрук, науч. сотр.,

Л. Пакуляк, канд. физ.-мат. наук

Главная астрономическая обсерватория НАН Украины, Киев;

В. Лукьянчук, магистр,

Киевский национальный университет имени Тараса Шевченко, Киев

\section{ФОТОГРАФИЧЕСКИЕ НАБЛЮДЕНИЯ БОЛЬШИХ ПЛАНЕТ И ИХ СПУТНИКОВ В ГАО НАН УКРАИНЫ В 1961-1990 Г.}

В рамках национального проекта "Украинская виртуальная обсерватория" проведены работы по созданию каталогов астрономических положений и звездных величин больших планет и их спутников на базе архива фотографических наблюдений в ГАО НАН Украины с помощью четырех телескопов в период с 1961 г. по 1990 е. Благодаря программному комплексу, созданному в ГАО для редукции 
оцифрованных астронегативов, выполнена обработка спутников Сатурна (S2-S9), а так же планет Урана, Нептуна и их спутников U1-U4, N1. В качестве опорной системы выбрана система каталога TYCHO2. Внутренняя точность определений положений составила $\pm 0.09- \pm 0.25$ arcsec. В настоящее время выполняются работы по обработке рядов фотографических наблюдений Нептуна, Урана и их спутников, полученных в ГАО за этот же период.

Ключевые слова: каталоги, тела Солнечной системы, Сатурн, Уран, Нептун.

O. Yizhakevych, junior researcher, V. Andruk, researcher,

L. Pakuliak, Ph. D., MAO NAS of Ukraine;

V. Lukianchuk, magister,

Taras Shevchenko National University of Kyiv, Kyiv

\section{PHOTOGRAPHIC OBSERVATIONS OF MAJOR PLANETS AND THEIR MOONS IN MAO NAS OF UKRAINE DURING 1961-1990}

We present the results of digitizing and processing of archival observations to obtain the astrometric positions and stellar magnitudes of major planets and their satellites. The work has been done within the framework of the national project "Ukrainian Virtual Observatory" on the basis of photographic observations carried out in MAO NASU. The processing of digital images and the astrometric reduction of data was made in the software package created and developed in MAO for the reduction astrometric negatives. The catalogue includes data of Saturn's moons (S2-S9), obtained using 4 telescopes in 1961-1990. The stellar catalogue TYCHO2 was used as the reference. The internal positional accuracy is $\pm 0.09- \pm 0.25$ arcsec. The same procedure is now applying for the processing of photographic observations of Neptune, Uranus, and their moons, obtained in MAO during the same period.

Key words: catalogues, Solar System bodies, Saturn, Uranus, Neptune.

Удк 524.7

С. Парновський, д-р фіз.-мат. наук, Астрономічна обсерваторія Київського національного університету імені Тараса Шевченка, Київ

\section{ВИЗНАЧЕННЯ ПОЧАТКОВОЇ ФУНКЦІЇ СВІТНОСТІ ГАЛАКТИК З АКТИВНИМ ЗОРЕУТВОРЕННЯМ}

Показано, як визначити початкову функцію світності, що описує розподіл світності галактик при нульовому віці спалаху, на основі поточної функції світності вибірки галактик з активним зореутворенням.

Функція світності (ФС), яка описує розподіл світності галактик, є важливою статистичною характеристикою населення галактик $[1,5]$. Для галактик з активним зореутворенням, світність яких у лінії випромінювання На або в ультрафріолетовому континуумі сильно змінюється у проміжку часу близько декількох мільйонів років, треба розрізняти розподіл початкових світностей галактик та розподіл світностей галактик у вибірці, що досліджується. У роботі [3] введено поняття ФС для початкових світностей $L_{0}$, яку позначимо $n_{1}\left(L_{0}\right)$ та ФС для вибірки, яку позначаємо $n(L)$. У роботі [3] знайдено залежність між цими двома ФС, як у загальному випадку, так і в випадку закону еволюції світності галактик $L$, встановленому в роботі [4] на основі дослідження приблизно 800 компактних яскравих галактик з активним зореутворенням. Закон має вигляд

$$
L(T)=L_{0} \times f(T), \quad f(T)= \begin{cases}1 & T \leq T_{0} \\ \exp \left(-p\left(T-T_{0}\right)\right) & T>T_{0}\end{cases}
$$

де $T$ - проміжок часу після спалаху зореутворення. У роботі [3] було встановлено, що $T_{0}=3.2$ млн років, і значення

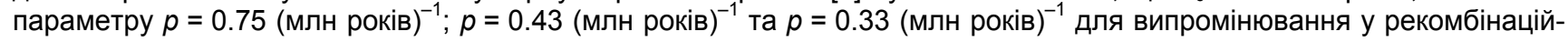
ній лінії Ha, FUV та NUV континуумі, відповідно. Залежність записується у вигляді

$$
n(L)=C\left(n_{1}(L)+q L^{1 / 2} \int_{L}^{\infty} x^{-3 / 2} n_{1}(x) d x\right) .
$$

Параметр $q=\left(p T_{0}\right)^{-1} \in$ фіксованим, параметр $C$ забезпечує потрібне нормування. Якщо обидві функції $n_{1}\left(L_{0}\right)$ та $n(L)$ нормуються однаково, то за результатами роботи [3] можна отримати $C=(1+2 q / 3)^{-1}$. За допомогою (2) у [3] отримано розподіл $n(L)$ за певними розподілами $n_{1}\left(L_{0}\right)$.

У статті розглянуто питання отримання початкової ФС $n_{1}\left(L_{0}\right)$ за відомим розподілом $n(L)$, тобто розв'язку інтегрального рівняння (2). При всій важливості отримання початкової ФС, це питання є математичним і в певній ступені технічним, тому воно розглядається окремо.

Рівняння (2) стосується певного узагальнення лінійних інтегральних рівнянь Вольтерри 2-го роду, але його ядро залежить тільки від $x$, що дає можливість отримати розв'язок. Для цього множимо (2) на $L^{-1 / 2}$ і беремо похідну. Отримуємо диференційне рівняння на $n_{1}$, яке розв'язується підстановкою $n_{1}(L)=L^{q+1 / 2} z(L)$. Пропустимо деталі розрахунку і наведемо розв'язок, який має вигляд

$$
n_{1}\left(L_{0}\right)=\left(1+\frac{2 q}{3}\right)\left(n\left(L_{0}\right)-q L_{0}^{q+1 / 2} \int_{L_{0}}^{\infty} n(x) x^{-q-3 / 2} d x\right) .
$$

